\title{
Computational Simulation of Acoustic Fatigue for Hot Composite Structures
}

Surendra N. Singhal

Sverdrup Technology, Inc.

Lewis Research Center Group

Brook Park, Ohio

Pappu L.N. Murthy and Christos C. Chamis

National Aeronautics and Space Administration

Lewis Research Center

Cleveland, Ohio

Vinod K. Nagpal and Edhi Sutjahjo

Sverdrup Technology, Inc.

Lewis Research Center Group

Brook Park, Ohio

Prepared for the

32nd Structures, Structural Dynamics, and Materials Conference cosponsored by AIAA, ASME, ASCE, AHS, and ASC

Baltimore, Maryland, April 8-10, 1991

\section{N/SA}

( VASA-1\%-104379) CNMOUATITAL SIMULATIUN

JF ACOUCTIC FATIGUL FOR HOT LOAPOSITC

STKULTUQES (NASA) IB 



\title{
COMPUTATIONAL SIMULATION OF ACOUSTIC FATIGUE FOR HOT COMPOSITE STRUCTURES
}

\author{
Surendra N. Singhal \\ Sverdrup Technology, Inc. \\ Lewis Research Center Group \\ Brook Park, Ohio 44142 \\ Pappu L.N. Murthy and Christos C. Chamis \\ National Aeronautics and Space Administration \\ Lewis Research Center \\ Cleveland, Ohio 44135 \\ Vinod K. Nagpal and Edhi Sutjahjo \\ Sverdrup Technology, Inc. \\ Lewis Research Center Group \\ Brook Park, Ohio 44142
}

\begin{abstract}
$\underline{\text { Abstract }}$
This report demonstrates predictive methods/computer codes for computational simulation of acoustic fatigue resistance of hot polymer-matrix composite structures subjected to acoustic excitation emanating from an adjacent vibrating component. Select codes developed over the past 2 decades at the NASA Lewis Research Center are used. The capabilities of computer codes include computation of (1) acoustic noise generated from a vibrating component, (2) degradation in material properties of the composite laminate at use temperature, (3) dynamic response of acoustically excited hot multi-layered composite structure, (4) degradation in the ply failure strength of the excited structure due to acoustic loading, and (5) acoustic fatigue resistance of the excited structure, including propulsion environment. Effects of the laminate configuration and environment on the acoustic fatigue life are evaluated. For the cases examined, the results show that by keeping the off-axis plies on the outer surface of the laminate, a substantial increase in the acoustic fatigue life is obtained. The effect of environment (elevated temperature and moisture) is to relieve the residual stresses leading to an increase in the acoustic fatigue life of the excited panel. The simulation methods/codes discussed in the present paper will be useful in assessing the acoustic fatigue life of propulsion components.
\end{abstract}

\section{Introduction}

Acoustic fatigue is one of the concerns in the design of aerospace propulsion structures. With increasing demands for performance and reliability of these structures, their acoustic fatigue resistance is becoming a critical design factor. Experiments to study acoustic fatigue are generally expensive and require a relatively long time to develop the test method, conduct the experiments, and interpret the results. Yet, one may not get all the answers. Consequently, computational simulation of acoustic fatigue 
is essentially inevitable. The computational simulation of acoustic fatigue becomes even more important for future high speed transport systems involving high intensity acoustic excitation from engine combustion processes and complex thermo-mechanical loads due to hypersonic flow as well as high temperature composites. Sound levels of up to 170 decibels can be produced by turbojet engines and for scramjet engines, sound levels can reach up to 185 decibels ${ }^{1}$. In addition to the direct exposure to acoustic excitation as generated by the engine, adjacent components are subjected to acoustic excitation loading (forced vibration-type) due to vibrations of various components.

NASA Lewis Research Center has been developing methods/multi-disciplinary computer codes for the computational simulation of the structural behavior of composite structures subjected to hygro-thermo-mechanical loadings over the past two decades. Select NASA codes provide the capability for calculating (1) acoustic noise level emanating from a vibrating structural component (code CSTEM ${ }^{2}$ ), (2) degradation in material properties of multi-layered composite laminates at use temperature (Code $\left.I C A N^{3}\right)$, (3) dynamic response of acoustically excited composite structures (code MHOST ${ }^{4}$ ), (4) degradation in the ply failure strength of the excited structure due to acoustic loading (code ICAN ${ }^{3}$ ), and (5) acoustic fatigue resistance of the excited structure, including propulsion environment (code $I C A N^{3}$ ).

The objective of the present report is to demonstrate application of these methods/codes for evaluating the acoustic fatigue response/resistance of hot polymermatrix composite structures excited by the acoustic noise generated from an adjacent vibrating component, including the effect of propulsion environment. Similar analysis can be performed for metal-matrix composites using code, METCAN ${ }^{5}$.

\section{Fundamental Considerations}

The simulation procedure is based on general analysis methods and is applicable for analyzing acoustic fatigue resistance of hot composite propulsion structures, excited by acoustic noise generated from adjacent components. The simulation is discussed for the acoustic fatigue response of a panel (labelled B), subjected to acoustic excitation emanating from an adjacent panel (labelled A), shown in Figure 1. The simulation approach is shown in Figure 2. Included in Figure 2, are names of codes used for computations at various stages of the analysis procedure. A brief description of the simulation approach follows and is outlined in Figure 2.

The panel $\mathrm{A}$, vibrating under a set of forcing functions of different forcing frequencies, generates sound power. The sound power emanating from various forcing frequencies is converted into acoustic pressure excitation on an adjacent panel $\mathrm{B}$. Then, dynamic analysis is performed on panel $B$, with the purpose of obtaining responses at the laminate level. These responses are subsequently used to determine the ply stresses using composite mechanics. During this phase of the simulation, the degradation in the strength of plies due to cyclic loading and hygrothermal environment is determined. The updated strengths are then used to estimate the acoustic fatigue life including the effect of thermal residual stresses at use temperature. The following are some of the fundamental considerations employed in the simulation approach. 
The component generating the acoustic noise (panel A) can be of isotropic or multilayered composite material and can be at room temperature or subjected to thermal loading allowing for temperature-dependent material properties. Thus the effect of temperature is reflected in the calculation of the stiffness matrix which, in turn, affects the acoustic noise generated from a hot component. First, the natural vibration frequencies and mode shapes of the vibrating component (panel A) are determined. Then, radiation efficiencies are determined for each mode, as a function of frequency based on the mode shapes. The sound power produced by the forced vibration of the component (panel A) is found by a modal summation of the contribution of each mode. A portion of the component generating the acoustic noise can be masked, thus eliminating the noise generated from a part of the component surface $e^{6,7,8}$. The sound power can be calculated for a number of forcing frequencies. The sound power, in turn, can be converted into acoustic pressure which becomes the acoustic loading on adjacent components (panel B). The acoustic pressure distribution on the surface of panel $B$ is taken to be uniform. The effect of factors such as attenuation of noise due to intervening medium, reflection of sound waves, and nonuniform pressure distribution, can be readily included.

If the propulsion structure is exposed to direct acoustic noise from an engine component in addition to that from an adjacent vibrating structure, the resultant acoustic pressure can be computed ${ }^{6}$. The computational method discussed in the present paper would be equally applicable for the total acoustic pressure distribution on the structure, irrespective of the noise source.

The component subjected to acoustically generated pressure excitation (panel B) can be made of isotropic or multi-layered composite material and can be at room temperature or subjected to thermal loading. The degradation in the material properties of hot composite is accounted for in the calculation of dynamic response of the component. The dynamic response of the acoustically excited component is calculated using a finite element approach based on a direct integration algorithm. Rayleigh damping with mass and stiffness proportional coefficients is used. However, it should be noted that damping depends on the configuration, constituent damping properties, and hygrothermal conditions as shown in reference 9. Currently, the methodologies to predict damping are being incorporated into the composites analysis code ICAN ${ }^{3}$, so that the effects of damping can be more systematically studied. This will be reported in future publications.

The effect of environment (temperature and humidity) is included in the calculation of acoustic fatigue life. The fatigue life or the number of cycles survived for a specific set of loading/environment, is estimated based on first ply failure criteria. Another important consideration is the inclusion of residual stresses due to curing process. Their effect, in general, is to reduce the life at room temperature conditions. However, any increase in temperature relieves the residual stresses. Furthermore, increased use temperature usually reduces both the stiffness and the strength of the matrix. Thus, there are competing issues which either increase or decrease the acoustic fatigue life of composite structures. This necessitates specific analyses on a case by case basis in order to arrive at an accurate estimation of acoustic fatigue life. The details of the 
formal procedure for calculating the fatigue life can be found in references ${ }^{10,11}$.

Computational Simulation of Acoustic Fatigue

A step-by-step general-purpose procedure for the computational simulation of acoustic fatigue is presented along with the specifics for a sample problem.

A simply supported rectangular 10" $\times 20$ " $\times 0.05$ " aluminum panel (labelled A in Figures 1 and 2) subjected to a sinusoidal force of $1000 \mathrm{lbs}$ (labelled $F$ in Figure 2) at a range of forcing frequencies from 10 to $10000 \mathrm{~Hz}$, is emitting noise (acoustic excitation). The acoustic excitation emanating from panel $A$ excites an adjacent simply supported rectangular 10" $\times 14 " \times 0.08$ " composite panel (labelled B in Figures 1 and 2) subjecting it to acoustic fatigue. Panel B is made of T300/IMHS (graphite fiber and intermediate strength epoxy composite) material with 0.55 fiber volume ratio. First, a base case is analyzed for panel B, consisting of a 16-ply $\left([0 / 45 /-45 / 90]_{2}\right)_{\text {s laminate at room }}$ temperature $\left(70^{\circ} \mathrm{F}\right)$ and zero humidity. Parametric studies are, then, conducted to investigate the effect of laminate configuration and environment on the acoustic fatigue resistance of the excited panel. The effects of laminate lay-up are examined for 2 cases; $\left([45 / 0 /-45 / 90]_{2}\right)_{s}$ and $\left([45 /-45 / 0 / 90]_{2}\right)_{s}$ laminates. The effects of environment are examined for 5 cases with different temperature and moisture absorption of the panels.

Table 1 lists a summary of the parameters used for these cases. The temperaturedependent material properties of aluminum used for panel $\mathbf{A}$ are listed in Table 2. The room temperature properties of T300/IMHS constituent materials for panel B are listed in Table 3.

The simulation procedure is outlined in Figure 3. A brief description of each step follows.

\section{Step-1: Acoustic noise generated from panel A}

The sound power generated from a vibrating component is calculated for a set of forcing frequencies. For each forcing frequency, the sound power is summed over a specified number of natural vibration modes of the exciting component. The corresponding computations are performed using a Coupled Thermal, Structural, and Electromagnetic Analysis/Tailoring code, CSTEM².

For the sample problem, the sound power is calculated for a set of 20 logarithmically distributed forcing frequencies $(10$ to $10000 \mathrm{~Hz}$ ). The sound power for each forcing frequency is summed over 8 natural vibration modes of the exciting panel. Modal loss factors ${ }^{6}$ of 0.02 are used for all eight modes. 


\section{Step-2: Acoustic Excitation for panel B}

The second step is to determine the resultant acoustic pressure loading on the acoustically excited component.

For the sample problem, the worst case scenario is assumed, i.e. the resultant acoustic pressure on panel $B$ is, obtained by a point-by-point summation of pressure amplitudes in time for all 20 sinusoidal excitations. The history of the resultant acoustic pressure for the acoustically excited panel $B$ at room temperature is shown in Figure 4. The resultant acoustic pressure is applied uniformly on the face of panel $\mathrm{B}$. For the case where the vibrating panel $A$ is hot (case 7 in Table 1), the acoustic pressure levels are lower. This is due to the lower response frequencies produced by panel $A$ as a result of degradation in the properties of aluminum.

\section{Step-3: Degradation in Properties of Panel B}

The third step is to compute the degradation in composite material properties of panel B. Composite micro-mechanics and laminate theories ${ }^{12}$ are used to calculate the material properties of the composite at ply and laminate levels, starting from room temperature properties at the constituent (fiber/matrix) level. The underlying theory ${ }^{12,13}$ accounts for nonlinear and interactive effects of temperature and moisture on the properties of the constituents. Relevant equations are embedded in an Integrated Composite Analyzer code ICAN $^{3}$ used for this purpose.

\section{Step-4: Dynamic Response of Panel B}

The fourth step is to compute the dynamic response of the acoustically excited component. The corresponding computations are performed using the finite element code MHOST $^{11}$. The stresses generated due to a steady state temperature distribution are also computed using MHOST.

For the sample problem, the dynamic response history for the longitudinal moment resultant is shown in Figure 5. The moment resultants are generated for transverse and shear directions too. Their histories, not included here, are of similar nature as that of Figure 5, but with different values. Table 4 shows the peak and trough values of the moment resultants for all the cases considered. The moment resultants listed are at the center of the panel.

Rayleigh damping with mass and stiffness proportional coefficients of 0.05 and 0.00002 , respectively, is used. This is equivalent to a critical damping ratio of 0.02 at the fundamental natural frequency of panel B, and $>0.02$ for higher modes. The time step used is equal to $1 / 100$ th of the natural period of the fundamental mode.

Static stress resultants are also calculated for the effect of thermal loading. The thermal loading is applied as uniform temperature increases from the reference room temperature to the use temperature. The analysis can also be performed for temperature gradients through the thickness. Table 4 includes the results for static 
shear directions too. Their histories, not included here, are of similar nature as that of Figure 5, but with different values. Table 4 shows the peak and trough values of the moment resultants for all the cases considered. The moment resultants listed are at the center of the panel.

Rayleigh damping with mass and stiffness proportional coefficients of 0.05 and 0.00002 , respectively, is used. This is equivalent to a critical damping ratio of 0.02 at the fundamental natural frequency of panel $B$, and $>0.02$ for higher modes. The time step used is equal to $1 / 100$ th of the natural period of the fundamental mode.

Static stress resultants are also calculated for the effect of thermal loading. The thermal loading is applied as uniform temperature increases from the reference room temperature to the use temperature. The analysis can also be performed for temperature gradients through the thickness. Table 4 includes the results for static stress resultants too.

\section{Step-5: Degradation in the Strength of the Panel B Due to Acoustic Load}

The fifth step is to compute the degradation in the strength of panel $B$, based on the first ply failure criterion, due to simultaneous application of static and cyclic load resultants calculated in the previous Step-4. The relevant equations to accomplish this are embedded in the computer code ICAN ${ }^{3,13}$. For the present study, only the node, which is most likely to fail first, based on the maximum amplitude of the cyclic loads, is selected for the estimation of acoustic fatigue life. The loads used in the analysis are given in Table 4. The failure criterion is based on the maximum strength criterion, i.e., in each ply, each in-plane stress is compared with the respective allowable strength. Other criterion such as that based on combined stresses can also be used.

The degradation in strength is reprsented by a Margin of Safety, defined as

$$
\text { Margin of Safety (MOS) }=1-\frac{\sigma_{1}}{S_{\text {leyc }}}
$$

where $\sigma_{1}$ is the ply stress (longitudinal, transverse or in-plane shear). $\mathrm{S}_{\text {leyc }}$ is the updated ply strength in the appropriate loading direction which includes the effects of cyclic loads and thermal/moisture induced static loads. Based on this definition, it is clear that a zero margin of safety implies that the laminate has no more strength left to survive any additional cycles. Thus, it provides an assessment of the cyclic threshold for the laminate. Figure 6 shows the MOS curves for all the cases studied as functions of number of cycles. Based on this definition, it is clear that a zero margin of safety implies that in one of the plies, the stress has reached the respective strength and therefore, is on the verge of failure based on the maximum strength failure criterion. The cycles 
the current ply strength calculated using composite micro-mechanics and the stress response of the ply under the current loading and environmental conditions (temperature, moisture etc.). Next, the margin of safety is plotted versus the number of cycles and the fatigue life in terms of cycles is established based on zero margin of safety (Figure 6). It should be noted that the above procedure only gives the fatigue life of the laminate based entirely upon on the first ply failure. Thus, the laminate may be able to survive additional cycles due to the remaining healthy plies. Thus, the present approach provides a conservative estimate of life. Figures 7 and 8 show the acoustic fatigue life for various cases of laminate configuration and environment.

\section{General Discussion}

The effect of acoustic fatigue on the margin of safety for the various cases studied is shown in figure 6 . The margin of safety is a measure of degradation in the ply strength. A zero margin of safety implies that no more strength is left to take additional stress thereby yielding the total number of cycles the laminate survives under those specific conditions. In the calculations, the effect of residual stresses due to curing is also included.

From the plots in Figure 6, it appears that the base case where the use temperature is $70^{\circ} \mathrm{F}$, and moisture content is $0 \%$, the number of cycles survived is the least. The laminate configuration has a substantial effect on the margin of safety. Thus the cases 1 and 2 for which the $45^{\circ}$ plies are on the outer side, the margins of safety are among the greatest. Consequently, laminates of cases 1 and 2 have much greater fatigue life than that for the base case.

Addition of moisture and increased use temperature of the acoustically excited panel B improved the life substantially. This is to be expected because any increase in temperature relieves the residual stresses.

The effect of laminate configuration on the acoustic fatigue life of the acoustically excited composite panel B is shown in figure 7. As mentioned earlier, by keeping the off-axis plies on the outer surface of the laminate, a substantial increase in the fatigue life is obtained. The effect of environment on the fatigue life is shown in figure 8 , where the life of the base case laminate is compared with the life for cases with varying degrees of moisture and temperature. It can be concluded that the effect of moisture and temperature is to increase the life due mainly to the residual stress relief with increase in the operating temperature and moisture. The last case (case 7) is unique compared to the rest of the cases because in here the aluminum panel generating the acoustic noise is vibrating at $200{ }^{\circ} \mathrm{F}$. Consequently, the acoustic pressure generated and thereby the magnitude of the cyclic load on the composite panel are significantly reduced. This resulted in a much higher fatigue life for the composite panel under case 7.

Although no experiments were conducted for verifying the results of the demonstration 
problem, results predicted for other cases, from the underlying theories have been compared with available experimental data and have been discussed with respect to their significance and application to design ${ }^{10}$.

\section{Concluding Remarks}

The acoustic fatigue of structural components subjected to acoustic noise from adjacent vibrating components in propulsion environment is simulated. Select codes developed at the NASA Lewis Research Center are used. Results for a sample problem are presented. Effects of composite laminate configuration and environment on the acoustic fatigue life are evaluated. The underlying theories account for the degradation of material properties due to environment, based on composite micro-mechanics and laminate theories. The influence of hygro-thermal loading is included. The effect of release of residual stresses due to temperature is considered.

For the sample problems discussed in this report, a substantial increase in the acoustic fatigue life is obtained by keeping the off-axis plies on the outer surface of the laminate. The decision on whether the off-axis plies be on the outer surface, will depend on all other design constraints. The addition of moisture and increased use temperature of the acoustically excited panel relieve residual stresses, improving the life substantially. The increase in the temperature of the acoustic excitation-source panel A decreased the acoustic pressure emanating from it, thereby increasing the acoustic fatigue life of the excited panel $\mathrm{B}$.

\section{References}

1. Blevins, R. D., "An Approximate Method for Sonic Fatigue Analysis of Plates and Shells", Journal of Sound and Vibration, vol. 129 (1), pp. 51-71, 1989.

2. Hartle, M., et. al., "CSTEM User's Manual", NASA Document, 1990.

3. Murthy, P. L. N. and Chamis, C. C., "Integrated Composite Analyzer (ICAN) Users and Programmers Manual, NASA TP-2515, 1986.

4. Nakazawa, "MHOST users Manual", NASA Document, 1987.

5. Murthy, P.L.N., Hopkins, D.A. and Chamis, C.C., "Metal Matrix Composite Micromechanics: In-situ Behavior Influence on Composite Properties", NASA TM$102302,1989$.

6. Fahy, F., "Sound and Structural Vibration Radiation, Transmission, and Response", Academic Press, London, 1985.

7. Hayes, P. E., "Determining Vibration, Radiation Efficiency, and Noise Characteristics of Structural Designs Using Analytical Techniques", Proceedings Society of Automotive Engineers, pp. 263-270, Warrendale, PA, 1982. 
8. Chamis, C. C., et. al., "Structural Tailoring of AGTE Components with CSTEM", presented at the Third Air Force/NASA Symposium, San Francisco, California, Spt. 24-26, 1990.

9. Saravanos, D.A., and Chamis, C.C., "Mechanics of Damping for Fiber Composites Laminates Including Hygrothermal Effects", AIAA Journal, Vol. 28, \#10, pp. 18131819, 1990.

10. Ginty, C. A. and Chamis, C. C., "Hygrothermomechanical Fiber Composite Fatigue", presented at the 33rd International SAMPE Symposium and Exhibition, Anaheim, California, March 7-10, 1988; NASA TM-100840, 1988.

11. Chamis, C.C. and Ginty, C.A., "Fiber Composite Structural Durability and Damage Tolerance: Simplified Predictive Methods, NASA TM 100179, 1987.

12. Chamis, C.C., "Simplified Composite Micro-Mechanics Equations for Hygral, Thermal, and Mechanical Properties", NASA TM-83320, 1983.

13. Chamis, C. C. and Sinclair, J. H., "Durability/Life of Fiber Composites in Hygrothermomechanical Environments", presented at the Sixth Conference on Composite Materials: Testing and Design, Sponsored by the American Society for Testing and Materials, Phoenix, Arizona, May 12-13, 1981; NASA TM-82749, 1981.

\section{Table 1: Laminate Configuration and Environmental Parameters for Various Cases of Acoustic Fatigue Simulation}

\begin{tabular}{|c|c|c|c|c|}
\hline \multirow[b]{2}{*}{ Case } & \multirow[b]{2}{*}{ Laminate Configuration } & \multicolumn{3}{|c|}{ Environment } \\
\hline & & $\begin{array}{c}\text { Temperature } \\
\text { of Panel A } \\
\left.\qquad{ }^{\circ} \mathrm{F}\right)\end{array}$ & $\begin{array}{c}\text { Temperature } \\
\text { of Panel B } \\
\left({ }^{\circ} \mathrm{F}\right)\end{array}$ & $\begin{array}{c}\text { Moisture Absorbed } \\
\text { by Panel B } \\
(\%)\end{array}$ \\
\hline Base Case & $\left([0 / 45 /-45 / 90]_{2}\right)_{S}$ & 70 & 70 & 0 \\
\hline Case 1 & $\left([45 / 0 /-45 / 90]_{2}\right)_{S}$ & 70 & 70 & 0 \\
\hline Case 2 & $\left([45 /-45 / 0 / 90]_{2}\right)_{S}$ & 70 & 70 & 0 \\
\hline Case 3 & $\left([0 / 45 /-45 / 90]_{2}\right)_{S}$ & 70 & 160 & 0 \\
\hline Case 4 & $\left([0 / 45 /-45 / 90]_{2}\right)_{S}$ & 70 & 200 & 0 \\
\hline Case 5 & $\left([0 / 45 /-45 / 90]_{2}\right)_{S}$ & 70 & 160 & 0.5 \\
\hline Case 6 & $\left([0 / 45 /-45 / 90]_{2}\right)_{S}$ & 70 & 200 & 1 \\
\hline Case 7 & $\left([0 / 45 /-45 / 90]_{2}\right)_{S}$ & 200 & 200 & 1 \\
\hline
\end{tabular}

Note: Fiber volume ratio $=0.55$ and void volume ratio $=0$ for all cases. 
Table 2: Temperature-dependent Properties for 6061 Aluminum for Hot Panel B

\begin{tabular}{|c|c|c|}
\hline & \multicolumn{2}{|c|}{ Temperature } \\
\hline Property & \multicolumn{2}{|c|}{$\left.{ }^{\circ} \mathrm{F}\right)$} \\
\hline $\begin{array}{c}\text { Modulus of } \\
\text { Elasticity } \\
\text { (Mpsi) }\end{array}$ & 11.86 & 11.09 \\
\hdashline $\begin{array}{c}\text { Poisson's } \\
\text { Ratio } \\
\text { (in/in) }\end{array}$ & 0.324 & 0.347 \\
\hdashline $\begin{array}{c}\text { Thermal } \\
\text { Expansion } \\
\text { Coefficient } \\
\text { (ppm/ }{ }^{\circ} \text { F) }\end{array}$ & 12.51 & 13.0 \\
\hline
\end{tabular}

Table 3: Constituent Material Properties of T300/IMHS at Room Temperature $\left(70^{\circ} \mathrm{F}\right)$

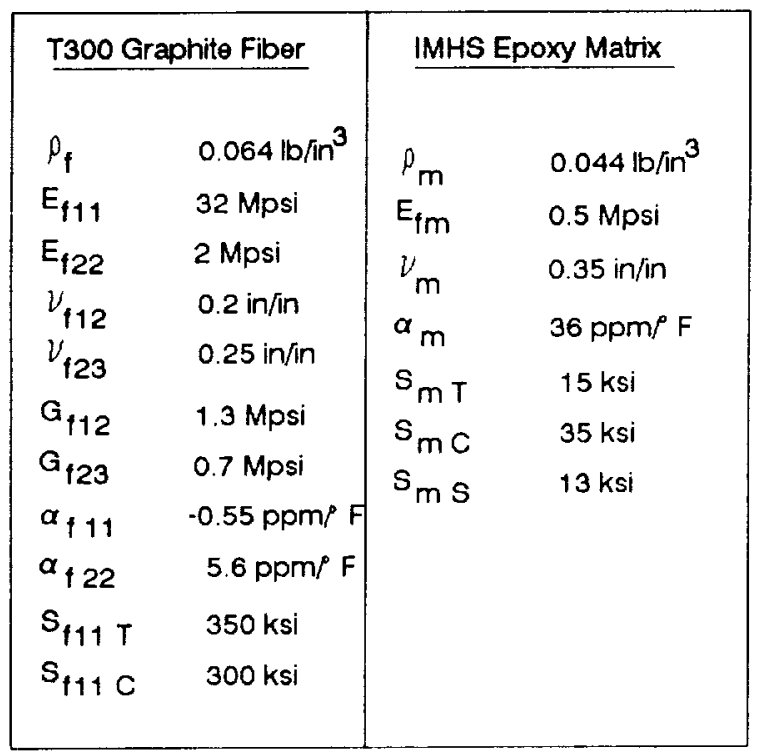

Notation:

E: Normal Modulus

G: Shear Modulus

$\mathrm{S}$ : Strength

$\rho$ : Density

$v:$ Poisson's Ratio

$\alpha$ : Thermal Expansion Coefficient

Subscripts:

c. Compression

f: Fiber

$\mathrm{m}$ : Matrix

s: Shear

$\mathrm{T}$ : Tension

11: Longitudinal

22: Transverse

12: In-plane

23: Out-of-plane 


\section{Table 4: Cyclic Tensile \& Compressive Acoustic Loading from Dynamic Force Response \& Static Thermal Response of Panel B}

\begin{tabular}{|c|c|c|c|c|c|c|c|c|c|c|c|c|}
\hline \multicolumn{4}{|c|}{ Case Description } & \multicolumn{6}{|c|}{$\begin{array}{l}\text { Cyclic Stress Resultants } \\
\text { from Acoustic Loading }\end{array}$} & \multicolumn{3}{|c|}{$\begin{array}{c}\text { Static Thermal Stress } \\
\text { Resultants }\end{array}$} \\
\hline \multirow{3}{*}{ Case } & \multirow{3}{*}{$\begin{array}{c}\text { Laminate } \\
\text { Configuration }\end{array}$} & \multicolumn{2}{|c|}{ Environment } & \multirow{2}{*}{\multicolumn{2}{|c|}{$\begin{array}{l}\text { Longitudinal } \\
\text { (lb-in/in) }\end{array}$}} & \multirow{2}{*}{\multicolumn{2}{|c|}{$\begin{array}{c}\text { Transverse } \\
\text { (lb-in/in) }\end{array}$}} & \multirow{2}{*}{\multicolumn{2}{|c|}{$\begin{array}{l}\text { Shear } \\
(\text { Ib-in/in) }\end{array}$}} & \multirow{3}{*}{$\begin{array}{l}\text { Long. } \\
\text { (Ib/in) }\end{array}$} & \multirow{3}{*}{$\begin{array}{l}\text { Trans. } \\
\text { (Ib/in) }\end{array}$} & \multirow{3}{*}{$\begin{array}{l}\text { Shear } \\
\text { (Ib/in) }\end{array}$} \\
\hline & & $\mathrm{T}^{\mathrm{T}}$ & $M$ & & & & & & & & & \\
\hline & & $\left({ }^{\circ} \mathrm{F}\right)$ & $(\%)$ & Peak & Trough & Peak & Trough & Peak & Trough & & & \\
\hline Base & $\left([0 / 45 /-45 / 90]_{2}\right)_{S}$ & 70 & 0 & 9.0 & -12.5 & 10.0 & -13.0 & 0.83 & -0.64 & 0 & 0 & 0 \\
\hline 1 & $\left([45 / 0 /-45 / 90]_{2}\right)_{S}$ & 70 & 0 & $5.41 \vdots$ & -5.54 & 4.78 & -5.13 & 0.97 & -0.92 & 0 & 0 & 0 \\
\hline 2 & $\left([45 /-45 / 0 / 90]_{2}\right)_{S}$ & 70 & 0. & 7.54 & -7.71 & 6.35 & -6.84 & 0.69 & -0.66 & 0 & 0 & 0 \\
\hline 3 & $\left([0 / 45 /-45 / 90]_{2}\right)_{S}$ & 160 & 0 & 8.43 & -11.02 & 9.70 & -12.72 & 0.81 & -0.62 & -159.0 & -159.0 & 0 \\
\hline 4 & $\left([0 / 45 /-45 / 90]_{2}\right)_{S}$ & 200 & 0 & 8.23 & -10.78 & 9.5 & -12.5 & 0.8 & -0.61 & -228.1 & -228.1 & 0 \\
\hline 5 & $\left([0 / 45 /-45 / 90]_{2}\right)_{S}$ & 160 & 0.5 & 8.32 & -10.9 & 9.6 & $\begin{array}{l}-12.61 \\
\ldots \ldots \ldots \ldots\end{array}$ & 0.8 & -0.61 & -158.6 & -158.6 & 0 \\
\hline 6 & $\left([0 / 45 /-45 / 90]_{2}\right)_{S}$ & 200 & 1 & 7.97 & -10.49 & 9.26 & -12.23 & 0.79 & -0.6 & -227.0 & -227.0 & 0 \\
\hline $7^{+}$ & $\left([0 / 45 /-45 / 90]_{2}\right)_{S}$ & 200 & 1 & 7.33 & -9.76 & 8.56 & -11.22 & 0.73 & -0.55 & -227.0 & -227.0 & 0 \\
\hline
\end{tabular}

Vibrating Panel, A

Acoustically Excited Composite Panel, B
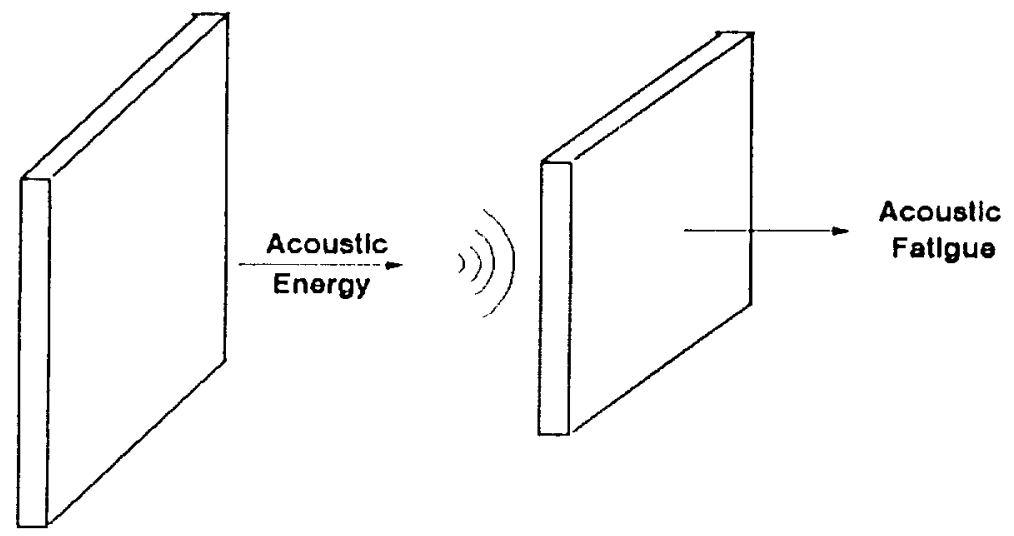

Figure 1.-Schematics of the acoustic fatigue simulation. 


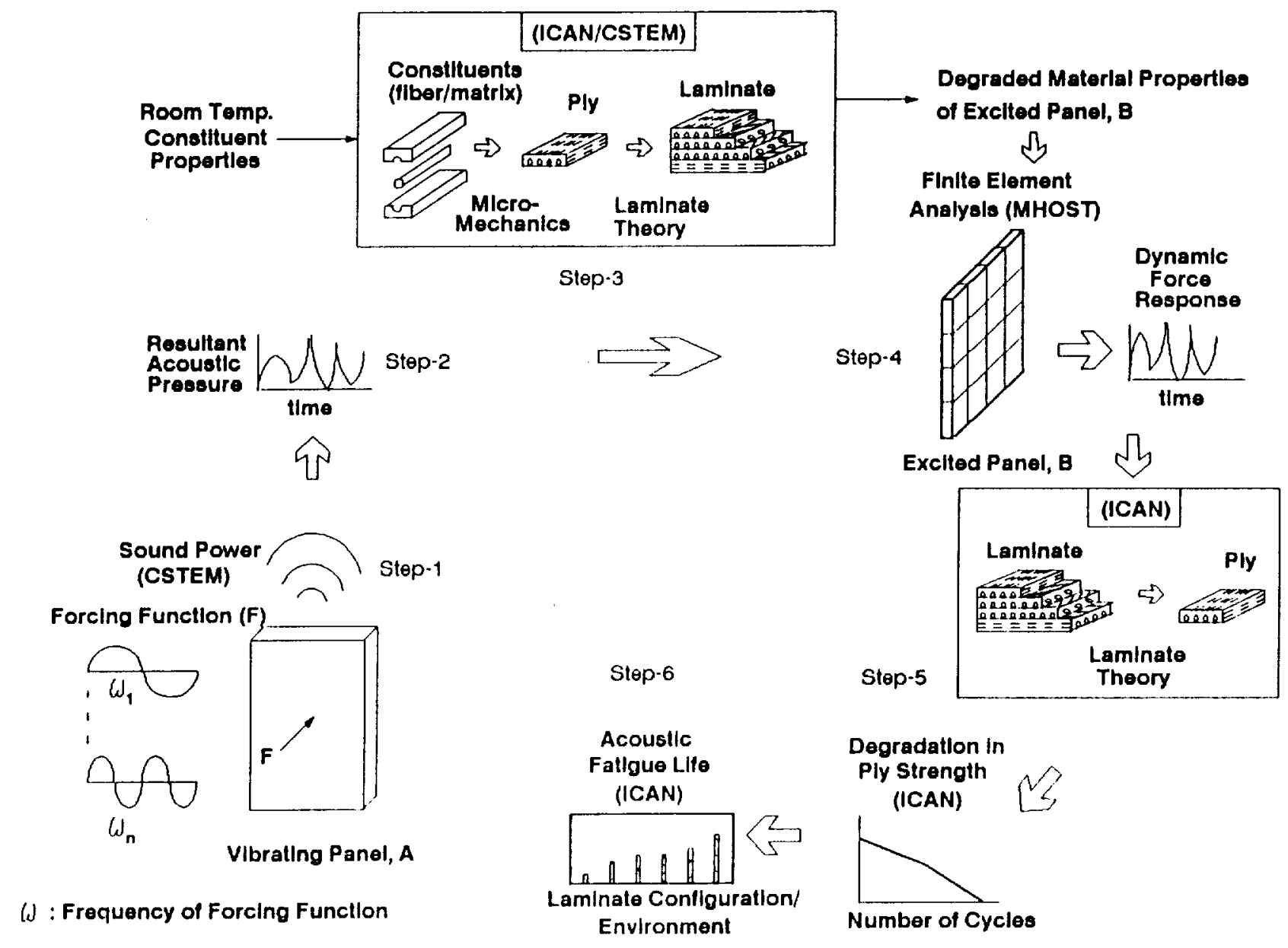

Figure 2.-Select NASA LeRC in-house codes simulate acoustic fatigue. 
Step-1: Compute Acoustic Power Generated from Panel A (code CSTEM).

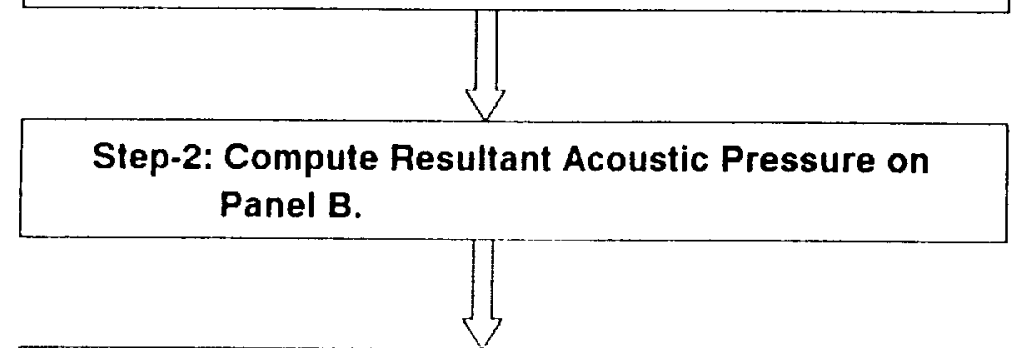

Step-3: Compute Properties of Panel B Material at Use Temperature (code ICAN).

Step-4: Determine Dynamic Response of Panel B (code MHOST).

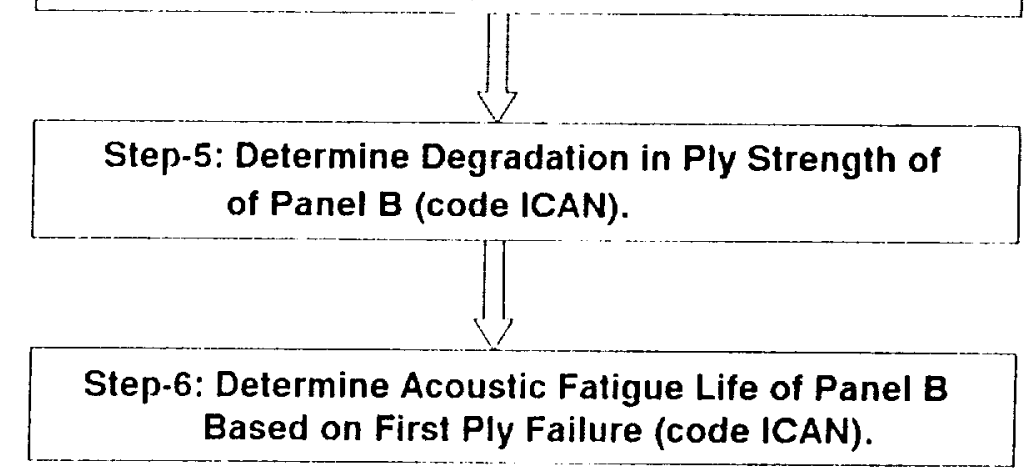

Figure 3.-Procedure for the simulation of acoustic fatigue. 


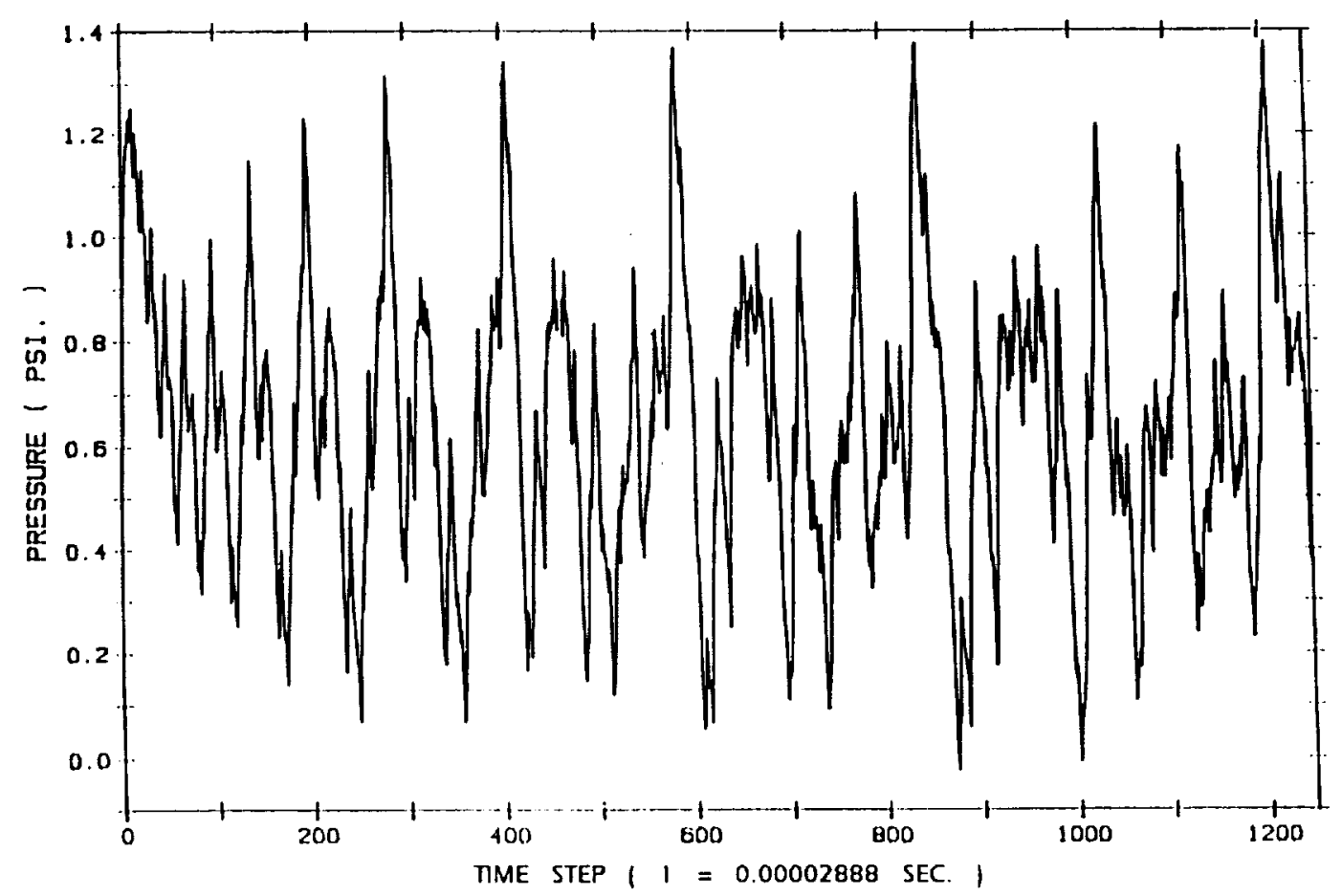

Figure 4.-Resultant acoustic pressure history for the base case.

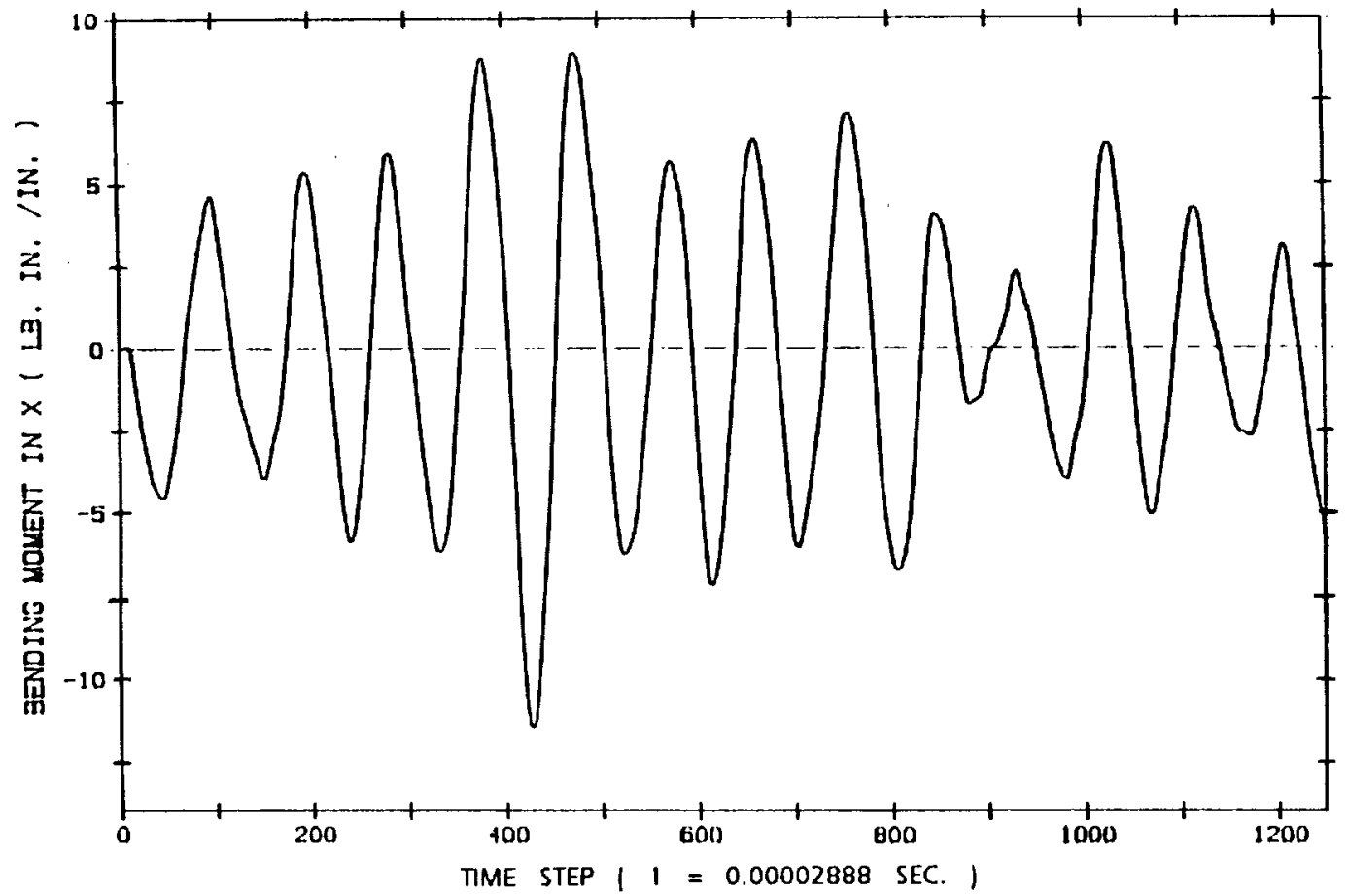

Figure 5.-Dynamic force response history of panel $\mathrm{B}$ for $\left([0 / 45 /-45 / 90]_{2}\right)_{\mathrm{s}}$; Laminate configuration, room temperature, and no moisture sorption (base case). 


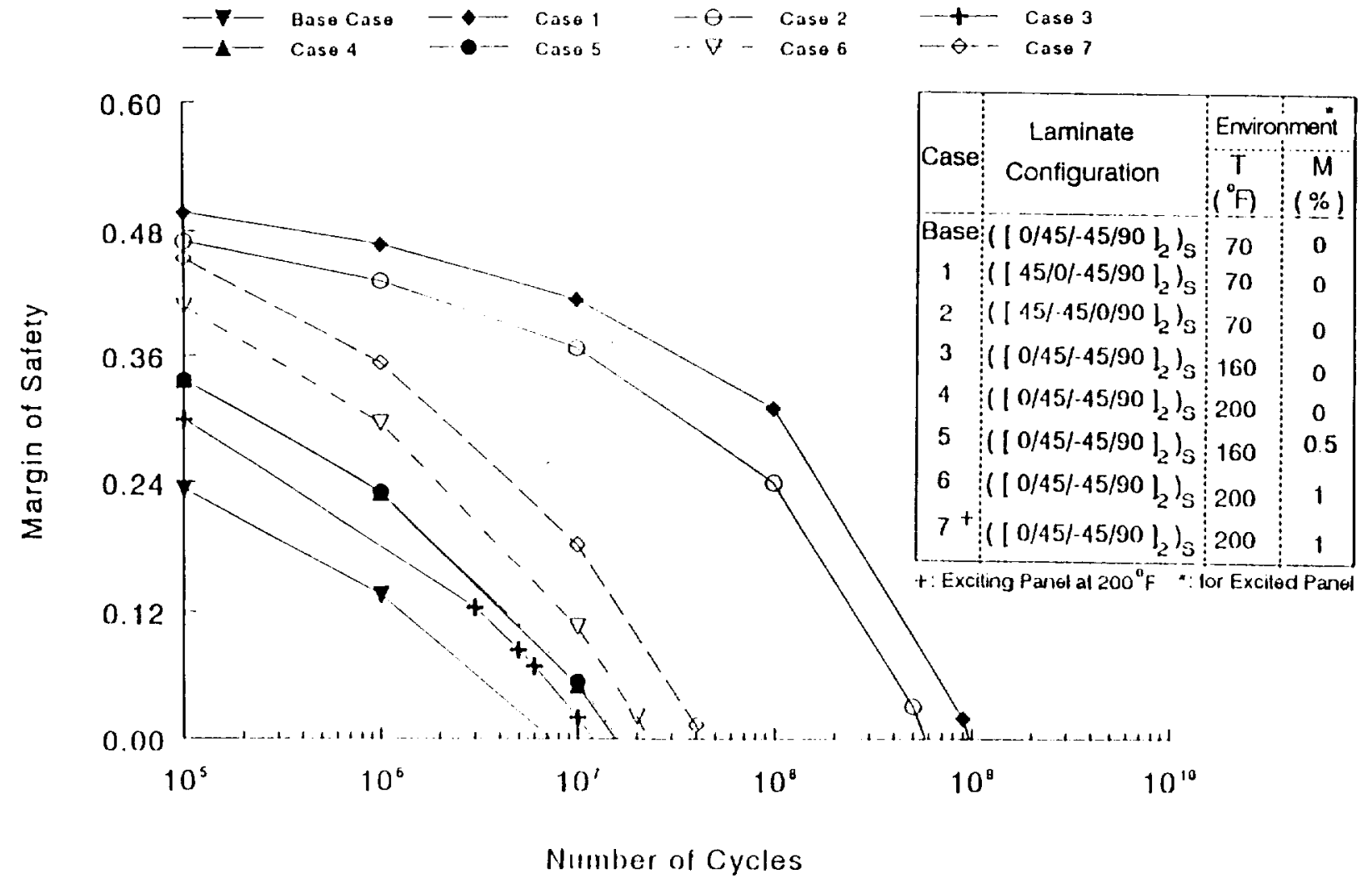

Figure 6.-Degradation in first ply strength of panel B due to acoustic fatigue.

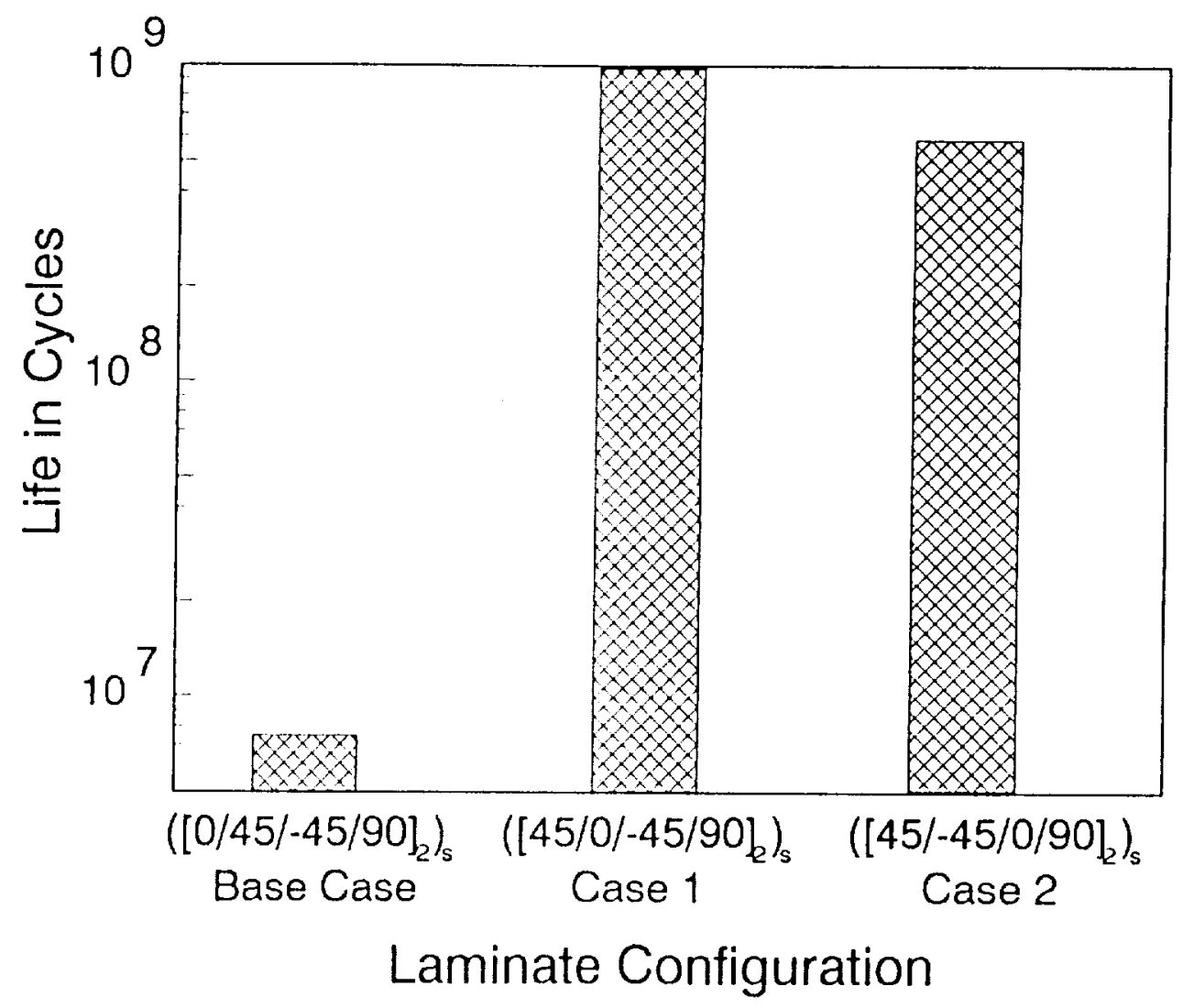

Figure 7.-Effect of laminate configuration on acoustic fatigue of panel B. 


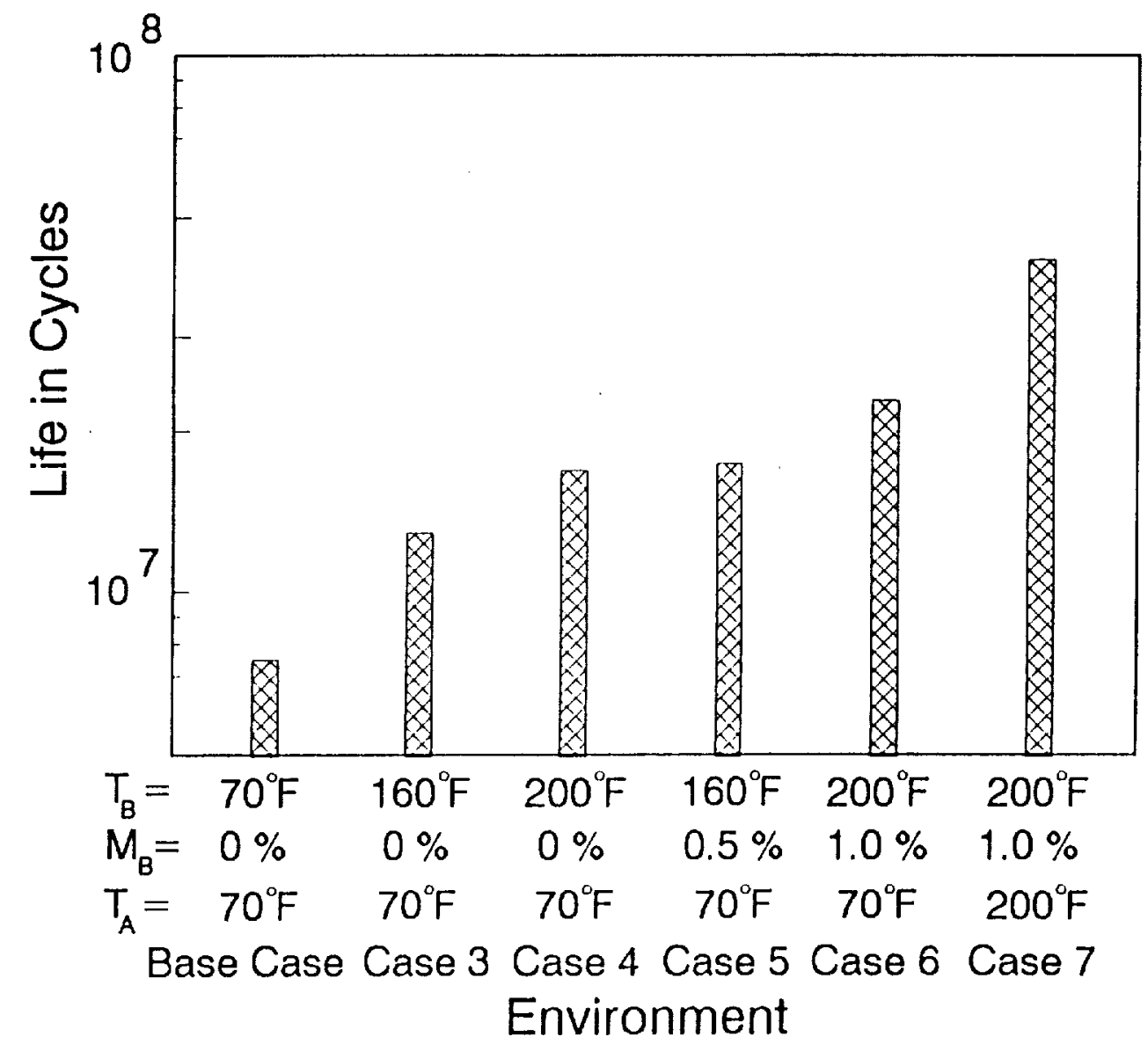

Figure 8.-Effect of environment on acoustic fatigue of panel B. 


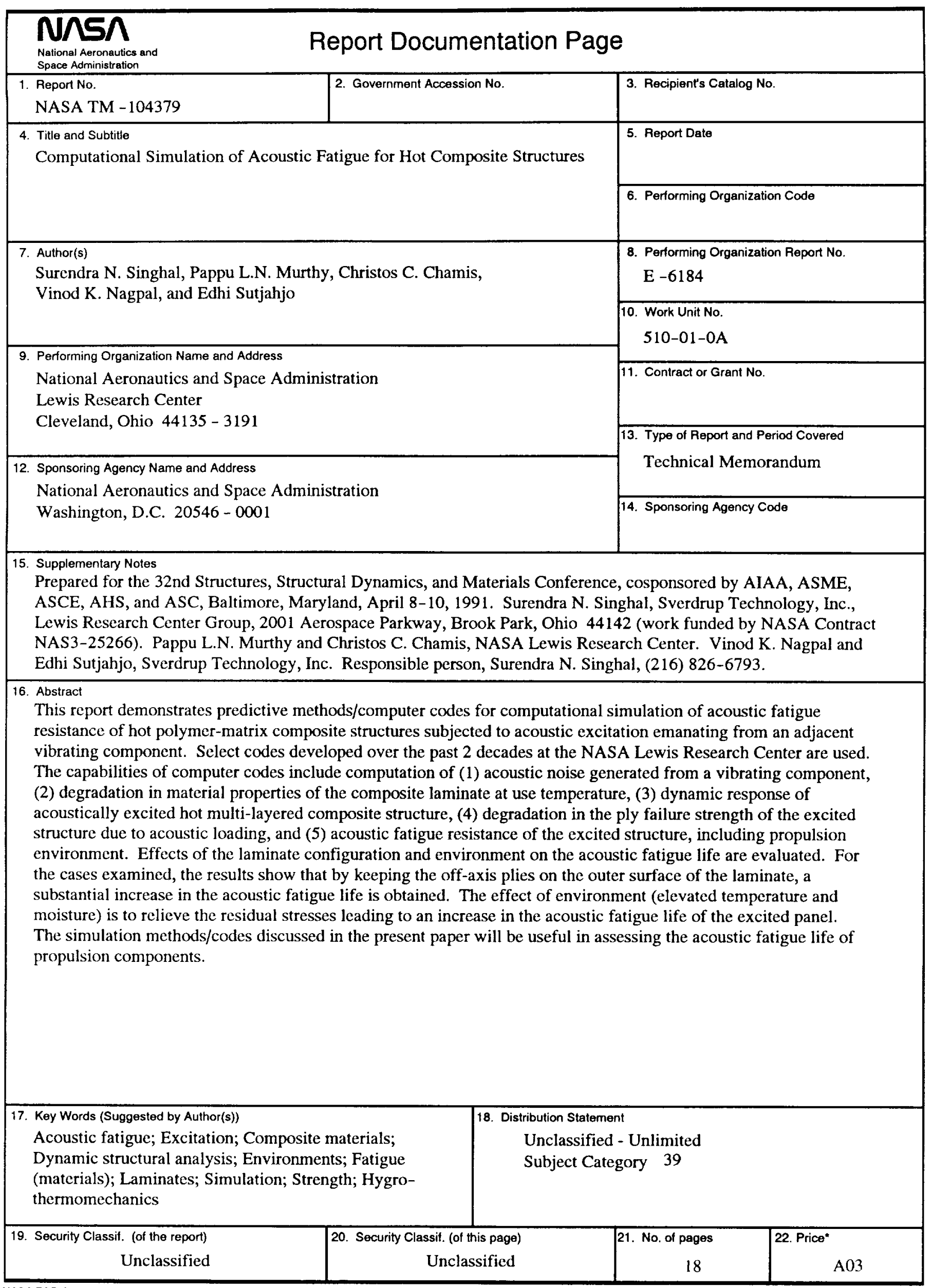


